\title{
The effects of relevant and irrelevant labels on short-term memory in nursery school children ${ }^{1}$
}

\author{
ELLEN S. BUSH and LESLIE B. COHEN, \\ University of Illinois. Urbana, Ill. 61801
}

Nursery-school children, ranging in age from 3.4 to 4.3 years, were divided randomly into threc groups to study the effects of labels on short-term memory. Ont group served as a control, receiving no labcls, one group was given labels suggesting the actual colors of the stimuli, and the third group was given irrelevant word labels for the colors. The results indicate that labeling, whether relevant or irrelevant. improves retention. Recency and primacy effects were found for all groups.

Atkinson, Bernbach, \& Hansen (1964) reported a method for investigating short-term memory in nursery-school children. In their design, several cards were shown to the child, one at a time, and then placed face down in front of him to form a horizontal row. After the last card was laid down, E showed $S$ a cue card, identical to one of the stimulus cards and asked $S$ to point to the face-down card that "was the same." This method proved to be an effective way of kecping $S$ interested for the length of the testing session.

Bernbach (1967) used a similar method to test the effects of labels on short-term memory with nursery-school children. In previous short-term memory studies with children, he had not found the S-shaped forgetting curve or recency or primacy effects, all of which are present in adult forgetting functions. Recent theories have suggested that these effects are due to rehearsal. In adults, the labeling, hence the rehearsal, is believed to be a covert process. He tested the hypothesis by dividing the children into two groups, labelers and nonlabelers. He found the results to be consistent with a rehearsal hypothesis, namely, that the effects common to adult forgetting functions were found only among the children who used the labels. He concluded that if Ss rehearse only the items they label, differences in short-term memory between adults and children are due to the effects of labeling rather than inherent differences in the memory process.

The present investigation was designed to test Bernbach's rehearsal hypothesis for relevant and irrelevant labels. Bernbach used only relevant labels. A procedure similar to the one described above was used to test whether verbalization of irrelevant labels would facilitate recall or interfere with it. Recency and primacy effects were also investigated.

\section{SUBJECTS}

Thirty children enrolled in the nursery-school program at the University of Illinois, Urbana, served as $S s$ in the experiment. The children ranged in age from 3.4 to 4.3 years, with a mean of 3.9 years. The children were assigned randomly to three groups with the requirement of five boys and five girls per group.

\section{STIMULI}

Materials to be remembered consisted of four colored rectangles. The colors were grey-blue, blue-green, violet, and salmon. These colors were chosen because they would be difficult for children to label. Each rectangle, $2 \frac{1}{2} \times 1 \frac{1}{2}$ in., was mounted on a $3 \frac{1}{2} \times 3$ in. piece of white cardboard. A color circle, 3 in. in diam, was used for the recall test. The circle was broken into quadrants, each quadrant being one of the stimulus colors.

\section{PROCEDURE}

Each $S$ was tested individually. The session consisted of a pretest and the test and lasted about $20 \mathrm{~min}$. After the session, $S$ was given a small bag of M\&Ms.

The pretest for the color-label group (CL) and the word-label group (WL) consisted of learning the labels to associate with each stimulus color. For the CL group, the labels were "blue," "green," "purple," and "orange," which suggested the actual stimulus colors. For the WL group, the irrelevant labels, "car," "dog," "house," and "ball" were used in the place of the color labels above. The criterion for learning the labels was eight successive correct responses. A time limit of $10 \mathrm{~min}$ was set to reach criterion. Only one $S$ failed to reach criterion in this time limit and was dropped from the study.

For the control group, the nonlabelers (NL), the pretest was designed to give $\mathrm{S}$ some experience with the stimuli but no opportunity to label them. E asked $S$ to sort the stimuli into as many piles as he liked (four, three, two, or one). S was informed that there were no right or wrong answers. This sorting procedure was done eight times, which equaled the average amount of pretest exposure to the stimuli for the $\mathrm{CL}$ and WL groups.

The test consisted of 12 trials of four stimulus cards. For each trial, the order of presentation was randomized by shuffling the cards. The method of presentation was adapted from Atkinson, Bernbach, \&
Hansen (1964). On each trial, the cards were shown to $\mathrm{S}$ successively. After a card was shown, it was placed face down on the table, so that once the four cards were presented they formed a horizontal row in front of $S$. After the last card was laid down, $S$ was given the color circle. $E$ then pointed to one of the face-down cards and asked $S$ to point to the one on the color circle that "was the same." $S$ responded by pointing to one of the quadrants of the color circle. In the CL and WL conditions, $S$ was instructed to give the "name" he had learned for the stimulus when each was presented and when he was identifying the face-down card. The serial position of the test card was randomized for each $S$, each position being used three times per $S$.

\section{RESULTS}

Table 1 gives the mean number of correct responses per $S$ for each experimental group. In order to test for differences between experimental groups and possible recency and primacy effects, a 2(sex) by 3(experimental group) by 4(serial position) mixed analysis of variance was computed. Significant differences were found among the groups $(F=5.63, \mathrm{df}=2 / 24, \mathrm{p}<.05)$ and for the serial position of the test card $(F=17.81$, $\mathrm{df}=3 / 72, \quad \mathrm{p}<.05)$. A Tukey A multiple-comparison test (Winer, 1962) was run on both of these significant effects. For the group effect, the Tukey A showed both the $C L$ and WL groups to be significantly higher than the NL group $(p<.05)$. It appears, therefore, that both relevant and irrelevant verbalization aided recall. The Tukey A for serial position showed that the fourth position resulted in significantly higher recall than did any other position, and that the first position resulted in significantly higher recall than did the second position $(p<.05)$. The former demonstrates the strong recency effect observed, while the latter shows the primacy effect. Figure 1 shows the mean number of correct responses, pooled across groups, as a function of serial position.

In addition, the Group by Serial Position effect approached significance $(F=2.035$, $\mathrm{df}=6 / 72, \quad \mathrm{p}<.10)$. This interaction apparently resulted from the fact that while all three groups clearly demonstrated the recency effect, the only group responding significantly more to the first position than to the second, i.e., showing the primacy effect, was Group NL $(\mathrm{F}=13.58, \mathrm{df}=1 / 9, \mathrm{p}<.05)$.

Table 1

Mean Number of Correct Responses in Test

\begin{tabular}{cccccc}
\hline & \multicolumn{1}{c}{ Group } & NL & CL & WL & Means \\
\hline \multirow{3}{*}{ Sex } & M & 4.2 & 6.6 & 6.8 & 5.7 \\
& $F$ & 5.4 & 6.6 & 6.6 & 6.2
\end{tabular}

\begin{tabular}{lrrr} 
Means $\quad 4.8$ & 6.6 & 6.7 \\
\hline
\end{tabular} 
Fig. 1. Recency and primacy effects.

\section{DISCUSSION}

As in the Bernbach (1967) study, the groups that verbalized had higher recall scores than the group that did not. The fact that the WL group did as well as the $C L$ group implses that any sort of verbalization is helpful for recall. Another possible explanation of this, besides the rehearsal hypothesis, could be based on differential attention. Ss in the NL group had to have their attention directed towards the test stimuli several times during the session (at times it was questionable whether or not they were really trying to remember the stimuli). The fact that most of the Ss in the NL group scored at chance or below levels seems to confirm this implication. Labels of any kind may have served to keep Ss' attention focused on the stimuli.

Bernbach only observed recency and primacy effects in the group that used labels. In this study, the recency effects were observed for all groups, even the NL group. The NL group also displayed a strong primacy effect. These effects may be related to the decrease in the number of stimuli used. Bernbach used eight stimuli, while this experiment used only four. However, even with the eight stimuli, it seems probable that at least recency effects would be found in the NL group if $S$ was paying attention, since the recent exposure to the stimuli would strengthen his memory trace.

In the pilot study for this experiment, another experimental group was included. This group used CVCs as labels. The group was dropped from the experiment because of the difficulty the children had learning the CVC-color associations. The testing method used for the pilot study was similar to the method used by Bernbach, with 16 trials per $S$ and eight stimulus cards per trial. This was cut because the sessions proved to be too lengthy to keep the children's interest.

The results of this study indicate that, while verbalization does aid recall in children, the differences between the forgetting functions of adults and children cannot be completely explained by a rehearsal hypothesis or by differential attention. Neither one of these explanations accounts for the recency or primacy effects found in the NL group.

\section{RFFERENCES}

ATKINSON, R. C., BERNBACH, H. A, \& HANSEN, D. N. Short-term memory with young children. Psychonomic Science, 1964, $1,255-256$

BERNBACH. H. A. The effect of labels on short-term memory for colors with nursery school children. Psychonomic Science, 1967. 7. 149-150.

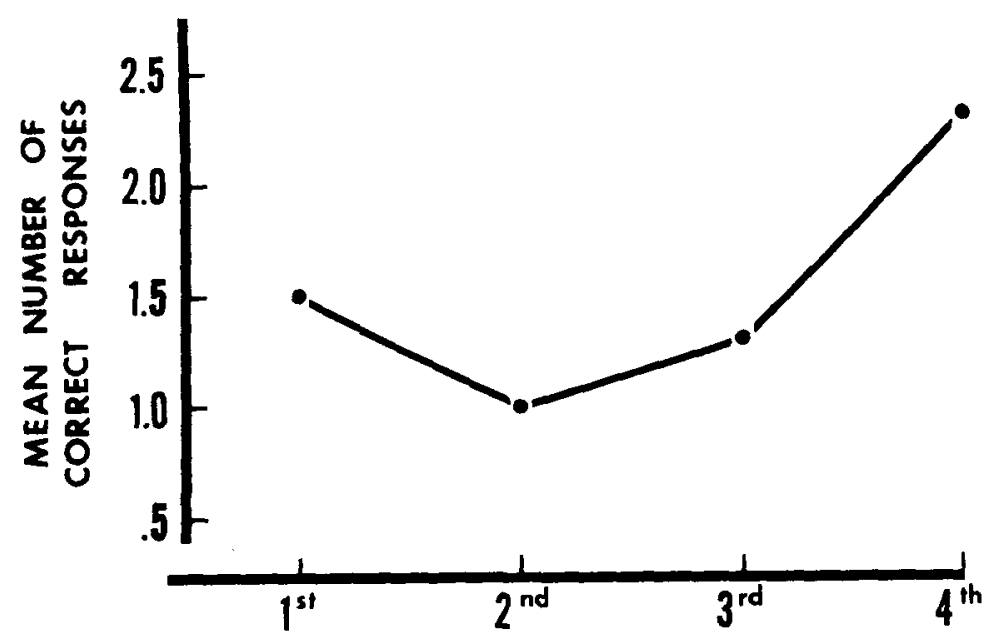

SERIAL POSITION

WINER, B. J. Statistical principles in experimental design. New York: McGraw-Hill, 1962.

1. This study was supported in part by a training grant in normal and retarded development, Grant HD 00244, from the National Institute of Child Health and Human Development, United States Public Health Service. Correspondence should be sent to Leslie B. Cohen, Psychology Department, University of. Illinois, Urbana, Ill. 61801.

\section{Effect of luminance in probability learning ${ }^{1}$}

JEANNE G. PORTER and HARRY $L$. MADISON, University of Wisconsin-Milwaukee, Milwaukee, Wis. 53201

Three groups of $40 \mathrm{Ss}$ predicted the occurrence of reinforcing lights differing in luminance in an Estes \& Straughan (1954) probability-learning situation. Little effect of luminance difference was found. It was concluded that the luminance effect reported by Nazzaro \& Todorov (1966) is, at most, a weak effect in this situation.

Nazzaro \& Todorov (1966) reported a preference in a two-choice probability-learning situation for predicting the brighter of two reinforcing lights, here called the "luminance effect." Using $12 \mathrm{Ss}$ per group over 200 trials, they found this effect when the brighter light occurred with $\pi=.75$ or .25 . It was not found when $\pi=.5$, but here they used only nine Ss per group. Madison \& Boudewyns (1967) reported a preference for predicting a single reinforcing light as compared to predicting no-light, called the "asymmetric effect," with $\pi=.5$ or .7 . They suggested that the asymmetric effect could be an extreme case of the luminance effect. This raises the interesting possibility of relating the physical properties of a reinforcing stimulus to the parameters in probability-learning theory (Estes \& Straughan, 1954). 